\title{
ERRATUM
}

Patrick Frettinger - Sylvie Herrmann •

Frédéric Lapeyrie - Ralf Oelmüller · François Buscot

\section{Differential expression of two class III chitinases in two types of roots of Quercus robur during pre-mycorrhizal interactions with Piloderma croceum}

Published online: 17 May 2006

C) Springer-Verlag 2006

\section{Mycorrhiza (2006): DOI 10.1007/s00572-006-0036-y}

Unfortunately, Table 1 was published with errors. The correct Table 1 is given here.

The online version of the original article can be found at: http://dx. doi.org/10.1007/s00572-006-0036-y.

P. Frettinger $\cdot$ S. Herrmann · F. Buscot

Department of Terrestrial Ecology, Institute of Botany I,

University of Leipzig,

Johannisallee 21-23,

04103 Leipzig, Germany

\section{S. Herrmann}

Institute of Ecology, University of Jena,

Dornburger Straße 159,

07743 Jena, Germany

P. Frettinger · F. Lapeyrie

"Tree-Microbe Interactions Unit",

Institut National de la Recherche Agronomique,

Champenoux, 54280, France

P. Frettinger · R. Oelmüller

Institute of General Botany and Plant Physiology,

University of Jena,

Dornburger Straße 159,

07743 Jena, Germany

F. Buscot $(\bowtie)$

Center for Environmental Research (UFZ),

Department for Soil Ecology,

Theodor-Lieser-Straße 4,

06120 Halle, Germany

e-mail: buscot@uni-leipzig.de

Tel.: +49-341-9738581

Fax: +49-341-9738599 
Table 1 Degenerates primers used for polymerase chain reaction (PCR) on genomic DNA from Quercus robur and specific primers for QrchitIII-1 and QrchitIII-2 reverse transcription polymerase chain reaction (RT-PCR) and quantitative real-time PCR analysis

\begin{tabular}{|c|c|c|c|c|c|c|c|}
\hline Primer types & Oligonucleotide sequences & $\begin{array}{l}\text { Fragment } \\
\text { sizes }(b p)\end{array}$ & $\begin{array}{l}\text { Database } \\
\text { organism } \\
\text { matches }\end{array}$ & E-value & $\begin{array}{l}\text { Genbank } \\
\text { Accession } \\
\text { number }\end{array}$ & Primer specificity & \\
\hline \multirow[t]{2}{*}{$\begin{array}{l}\text { Degenerate primers }^{\mathrm{a}} \\
\text { for class III chitinases }\end{array}$} & $\begin{array}{l}\text { 5' GGN GAY GCN GTN } \\
\text { YTN GAY GG 3' }\end{array}$ & 198 to 201 & - & - & - & & \\
\hline & $\begin{array}{l}5^{\prime} \text { YTG NAC CCA NAC } \\
\text { GTA RTC RA 3' }\end{array}$ & & & & & & \\
\hline \multirow[t]{2}{*}{$\begin{array}{l}\text { Specific primers } \\
\text { for QrchitIII-1 }\end{array}$} & $\begin{array}{l}\text { 5' GAC TTT GAT ATT }^{\prime} \\
\text { GAA GGA GG 3' }\end{array}$ & 160 & $\begin{array}{l}\text { Dioscorea } \\
\text { oppositifolia }\end{array}$ & $9 \mathrm{e}-27$ & AJ879088 & & \\
\hline & $\begin{array}{l}\text { 5' ATA GAC CTG TCT }^{\prime} \\
\text { TAA GGG CAG C 3' }\end{array}$ & & & & & Q.r. & P.c. \\
\hline \multirow[t]{2}{*}{$\begin{array}{l}\text { Specific primers } \\
\text { for QrchitIII-2 }\end{array}$} & $\begin{array}{l}\text { 5' GAT TTT GGC ATT } \\
\text { GAG ATT GG 3' }\end{array}$ & 157 & Cicer arietinum & $2 e-16$ & AJ879089 & & \\
\hline & $\begin{array}{l}5^{\prime} \text { ACA AGC CGG TTT } \\
\text { TGA TAT CGG 3' }\end{array}$ & & & & & Q.r. & P.c. \\
\hline
\end{tabular}

The last column shows primer specificities to the plants, with amplifications with the cDNA of $Q$. robur and no amplification with the cDNA of $P$. croceum

Q.r. Q. robur, P.c. P. croceum

${ }^{\mathrm{a}}$ In degenerate primers $N \mathrm{~A}, \mathrm{C}, \mathrm{T}$, or $\mathrm{G}, Y \mathrm{C}$ or $\mathrm{T}, R \mathrm{~A}$ or $\mathrm{G}$ 